\title{
Mapping the human genome: An assessment of media coverage and public reaction
}

Ellen S. Tambor, $M A^{1,2}$, Barbara A. Bernhardt, $M S^{1-3}$, Joann Rodgers, $M S^{4}$, Neil A. Holtzman, $M D, M P H^{1-3}$, and Gail Geller, $S c D^{1-3,5}$

\begin{abstract}
Purpose: To assess public reactions to the June 26, 2000, announcement that scientists had nearly finished mapping the human genome. Methods: We conducted a random-digit telephone survey of 407 Maryland residents as well as a content analysis of 55 relevant media reports. Results: African Americans were more likely than Caucasians to report a negative reaction $(P<0.001)$ to the genome announcement. Overall, privacy/discrimination (16\%) and human cloning (14\%) were the most commonly mentioned concerns regarding the impact of the genome mapping. Conclusions: These findings highlight the need for continued public discourse, including through the media, to address concerns regarding the Human Genome Project. Genet Med 2002:4(1):31-36.
\end{abstract}

Key Words: Human Genome Project, genetics, genetic education, mass media, public opinion, minority opinions

The complete sequencing of the human genome has been among the most highly anticipated scientific achievements in recent history. When the announcement was made on June 26, 2000, that scientists with the Human Genome Project and Celera Genomics were close to completing maps of the human genome, ${ }^{1}$ the media response was enormous. One search of the Lexis-Nexis news database identified over 200 newspaper articles concerning the genome mapping during the 2 days surrounding the announcement. Discussion of the event in scientific publications has also been extensive. ${ }^{2-5}$ However, not much is known about public reactions to the sequencing of the human genome.

Studies assessing public attitudes toward new genetic technologies such as genetic screening and gene therapy have reported public enthusiasm for the health benefits promised by such technologies combined with concern about possible harms. ${ }^{6-10}$ These attitudes, as well as attitudes concerning the mapping of the genome, are likely to be influenced by any number of factors, including the messages conveyed by the media. Although the media is for many Americans a primary source of health and science information, media coverage of genetics is selective and presented within particular frameworks. ${ }^{11-13}$

The view is commonly expressed that public understanding of science, and genetics in particular, is important so that society can play a role in determining the direction and applica-

From the ${ }^{1}$ Department of Health Policy and Management, School of Hygiene \& Public Health, Johns Hopkins University; ${ }^{2}$ Genetics \& Public Policy Studies, Department of Pediatrics, Johns Hopkins School of Medicine; ${ }^{3}$ Institute of Genetic Medicine, School of Medicine, Johns Hopkins University; ${ }^{4}$ Office of Communications and Public Affairs, School of Medicine, Johns Hopkins University; ${ }^{5}$ Phoebe Berman Bioethics Institute, Johns Hopkins University, Baltimore, Maryland.

Gail Geller, ScD, Johns Hopkins Medical Institutions, 550 N. Broadway, Suite 511, Baltimore, MD 21205.

Received: August 9, 2001.

Accepted: November 1, 2001. tion of scientific research. ${ }^{14-16}$ Given the extensive coverage of the genome announcement in the popular press, it is likely that a large segment of the population is at least aware that the mapping of the human genome has occurred. In the present study, we assessed public awareness of and reactions to the genome mapping announcement, as well as perceptions of the media coverage surrounding the announcement. In addition, we conducted a content analysis of a subset of media reports that were cited by survey participants as a source of their information about the genome mapping. The study reported here is part of a larger project to examine the reporting of new genetic discoveries by the media.

\section{METHODS}

\section{Consumer telephone survey}

We conducted a telephone survey of Maryland residents between July 6 th and July 10 th, 2000. A survey research firm was contracted to carry out the survey using trained interviewers.

\section{Sampling and data collection}

Maryland households were sampled using a random digit dialing approach. Anyone age 18 or over was eligible to participate in an interview and only one individual could participate per household. Interviewers were instructed to continue recruitment until a target sample size of at least 225 completed (see below) interviews was reached. The overall study was approved by the Johns Hopkins Joint Committee on Clinical Investigation. The interviews were conducted anonymously, and no identifying information was recorded, therefore, written consent was not required.

Respondents were first asked if they had heard about the recent announcement that scientists had completed mapping the human genome. If they had not, the interviewer asked only the set of demographic questions before concluding the interview. If they had heard about the announcement, the inter- 
viewer asked where they had heard about it. Anyone who cited at least one media source (newspaper, magazine, television, radio, or internet) as a source of information completed the entire survey. Because we were assessing reactions to media coverage, those who had heard about the announcement but did not name a media source (i.e., they heard it from a friend or relative) completed only the demographic questions. Respondents who cited a media source were asked three closed-ended questions regarding their exposure to information about the mapping of the human genome (how much they had seen or heard about the announcement, how much they heard about the human genome project before the announcement, and their opinion on the quantity of media coverage about the announcement).

The remainder of the interview consisted of a series of openended questions regarding (1) respondents' initial reaction to the human genome announcement, (2) what they remembered about the content of the media coverage and the message conveyed by the media, and (3) what they believe the significance of the human genome mapping is for people in general (including the timing of any potential impact). In commenting on the media coverage (item 2 above), respondents were asked to think about a particular article or news report they remembered or, if they could not recall a specific story, to think in general about the media coverage. The interviewers recorded responses verbatim and used general probes (e.g., "Anything else?" "Can you explain?" "Any other positive or negative outcomes?") to solicit a complete response. The interviews concluded with demographic questions.

\section{Coding and analysis}

Based on an initial review of the data by members of the project team, it was determined that responses to all three of the questions listed above could be classified as Positive, Negative, or Neutral in nature. Although this classification involved some degree of subjectivity, most responses could be clearly assigned to one of the three categories and a high level of agreement between independent coders was achieved.

An initial set of 20 interviews were coded independently by the project coordinator and a research assistant with intercoder reliability of over $80 \%$. The remaining interviews were coded by the research assistant, then reviewed by the project coordinator for completeness and accuracy of coding. $\mathrm{Nu}-$ meric codes were entered in SPSS for quantitative analysis. A variable was created for each of the three survey questions with all responses assigned to only one of the following categories: Positive Only, Negative Only, Positive and Negative, or Neutral. These three variables, as well as dichotomous variables comparing Positive Only to Negative Only/Mixed, became the primary dependent variables in all subsequent quantitative analyses. Chi square tests were used to assess factors associated with these outcome variables. They were followed by logistic regressions, which included variables with significant $(P<0.05)$ bivariate associations.

\section{Analysis of media reports}

Respondents to the telephone survey were asked to name a specific media source from which they heard or read about the genome mapping announcement (i.e., the name of a newspaper or news broadcast). News reports were identified by searching the Lexis-Nexis database using the keywords "human genome" and the time frame June 26 through July 3, 2000. We collected all reports (printouts of articles or transcripts of radio and television broadcasts) pertaining to the genome announcement that appeared between these dates from sources cited by at least one respondent.

To begin the analysis, we reviewed a subset of reports and compiled a list of the topics covered. These topics were reduced to the following major content areas: (1) Description of what was done/educational information, (2) What remains to be done, (3) Who was involved (i.e., "the race" between NIH and Celera), (4) Medical implications, (5) Scientific implications, (6) Ethical issues, (7) Scientific limitations, (8) Opinions of experts, and (9) Opinions of public leaders. After establishing reliability between two coders of $>80 \%$, each report was read by one coder. The coder assigned each paragraph to one or more of the above categories based on the predominant theme of the paragraph. Paragraphs that did not fit any of the categories were assigned to an "other" category. We then calculated the proportion of each story devoted to each of the major content areas.

\section{RESULTS}

\section{Consumer survey}

Response rate and sample description

A total of 965 households were contacted, and $42 \%$ of the individuals contacted $(n=407)$ agreed to participate in the survey. A description of the sample is presented in Table 1. A majority were female and Caucasian. Ages ranged from 18 to 97 years (although there was no upper cutoff for age, only 8 of the respondents were over 80 and only 2 were over 90 years old). Almost all of the sample had at least a high school diploma.

\section{Proportion of sample who heard about the genome announcement}

Of the 407 individuals who agreed to participate, 58\% $(n=$ 237) said they had heard about the announcement and 230 individuals reported hearing about it from at least one media source and, therefore, completed the full survey. The remaining 177 respondents answered only the demographic questions.

Table 1 presents the proportion of respondents who had heard about the announcement by demographic characteristics. In logistic regression analysis, men were more than twice as likely as women to have heard, those with at least some college education were over five times as likely to have heard as those with no more than a high school diploma, individuals 40 years or older were almost four times as likely to have heard as 
Table 1

Demographic characteristics of sample and proportion who heard about announcement by demographic characteristics

\begin{tabular}{|c|c|c|c|c|}
\hline & \multirow{2}{*}{$\begin{array}{c}\text { Sample } \\
\text { distribution } \\
\%(N)\end{array}$} & \multirow[b]{2}{*}{$\begin{array}{c}\text { Heard }^{a} \\
(\%)\end{array}$} & \multicolumn{2}{|c|}{ Logistic regression } \\
\hline & & & $\begin{array}{l}\text { Odds } \\
\text { ratio }\end{array}$ & $\begin{array}{c}95 \% \\
\text { CI }\end{array}$ \\
\hline \multicolumn{5}{|l|}{ Sex } \\
\hline Male & $37.1(147)$ & 70.5 & 2.57 & $1.5-4.3$ \\
\hline Female & $62.9(249)$ & 51.4 & & \\
\hline \multicolumn{5}{|l|}{ Education } \\
\hline Some college + & $63.4(251)$ & 71.1 & 5.66 & $3.4-9.4$ \\
\hline HS or less & $36.6(145)$ & 36.5 & & \\
\hline \multicolumn{5}{|l|}{ Age } \\
\hline 40 and over & $64.4(251)$ & 67.5 & 3.98 & $2.4-6.6$ \\
\hline Under 40 & $35.6(139)$ & 42.0 & & \\
\hline \multicolumn{5}{|l|}{ Race } \\
\hline Caucasian/other & $78.5(292)$ & 62.2 & 2.24 & $1.3-4.0$ \\
\hline African American & $21.5(80)$ & 42.9 & & \\
\hline
\end{tabular}

CI, confidence interval; HS, high school.

${ }^{a}$ All $P \leq 0.001$.

those younger than 40 , and Caucasians/others were twice as likely as African Americans to have heard about the announcement.

When asked where they had seen or heard about the genome announcement: $60 \%$ of the 230 respondents who completed the full survey said they heard about it on television, $27 \%$ said newspaper(s), $10 \%$ said radio, $3 \%$ said magazine(s), and $1 \%$ said the internet. Respondents under the age of 30 were significantly more likely to have heard about the announcement from television than those age 30 and over ( $84 \%$ vs. $57 \%, P<$ $0.05)$. Individuals with a college degree or higher were more likely to have read about the announcement in a newspaper or magazine ( $37 \%$ vs. $23 \%$ ) and less likely to have heard about it from television ( $56 \%$ vs. $66 \%, P<0.05)$ than those with less than a college degree.

\section{Initial reactions to genome announcement}

When asked about their first reaction to the announcement, $47 \%$ of those surveyed gave exclusively positive responses. Of these 108 respondents, $72 \%$ mentioned the potential to prevent or treat disease as a result of the Human Genome Project: "I thought it was fantastic that scientists would be able to cure previously incurable diseases," "Scientists can find a cure for Alzheimer disease." The remaining 28\% made generally positive remarks: "I think it's a marvel, great potential."

Twenty-one percent of respondents $(n=49)$ described their reaction to the announcement as exclusively negative. Their comments ranged from religious concerns: "Let God do God's work," to ethical concerns: "Could be invasion of privacy by health insurance and employers," to generally negative remarks: "I think it's kind of scary."
Nine percent of respondents commented on both the potential for benefit and the possibility of harm that could result from the human genome mapping: "Two things-possibility of using to cure disease and concern that might lead to invasion of people's privacy." The remaining $23 \%$ of respondents reacted neither positively nor negatively to the announcement: "I am curious to know what it is all about."

Table 2 presents initial reactions to the genome announcement by demographic characteristics and by type and level of exposure to information about the Human Genome Project. In a logistic regression analysis, African Americans were three

Table 2

Initial reaction by demographics and exposure to information about genome project

\begin{tabular}{|c|c|c|}
\hline & $\begin{array}{c}\text { Positive } \\
\text { only } \\
(\%)\end{array}$ & $\begin{array}{c}\text { Negative/mixed } \\
(\%)\end{array}$ \\
\hline \multicolumn{3}{|l|}{ Demographics $(N)$} \\
\hline \multicolumn{3}{|l|}{ Sex } \\
\hline Male (103) & 60.9 & 39.1 \\
\hline Female (126) & 60.2 & 39.8 \\
\hline \multicolumn{3}{|l|}{ Education } \\
\hline HS or less (51) & 69.0 & 31.0 \\
\hline Some college (70) & 49.1 & 50.9 \\
\hline College grad + (108) & 64.1 & 35.9 \\
\hline \multicolumn{3}{|l|}{ Age } \\
\hline$<30(25)$ & 52.9 & 47.1 \\
\hline $30-39(31)$ & 48.0 & 52.0 \\
\hline $40-49(50)$ & 50.0 & 50.0 \\
\hline 50-59 (59) & 59.6 & 40.4 \\
\hline$>59(60)$ & 78.8 & $21.2^{a}$ \\
\hline \multicolumn{3}{|l|}{ Race } \\
\hline Caucasian/other ${ }^{b}(174)$ & 65.4 & 34.6 \\
\hline African American (34) & 33.3 & $66.7^{c}$ \\
\hline \multicolumn{3}{|l|}{ Media exposure } \\
\hline \multicolumn{3}{|l|}{ Where heard } \\
\hline Newspaper/mag. (67) & 34.0 & 66.0 \\
\hline TV/radio (160) & 20.3 & $79.7^{a}$ \\
\hline \multicolumn{3}{|l|}{ How much heard } \\
\hline A little (105) & 53.2 & 46.8 \\
\hline Fair amount/a lot (124) & 66.0 & 34.0 \\
\hline \multicolumn{3}{|l|}{ How much heard prior } \\
\hline Nothing/a little (160) & 58.5 & 41.5 \\
\hline Fair amount/a lot (70) & 65.5 & 34.5 \\
\hline
\end{tabular}

HS, high school; grad, graduate; mag., magazine.

${ }^{a} P<0.05$.

${ }^{b} N=5$ for "Other."

${ }^{c} P<0.001$. 
times as likely as Caucasians to have at least a partially negative response (Negative/Mixed versus Positive, odds ratio $=3.05$, $P<0.05)$. Negative reactions by African Americans were frequently of a religious nature: "Researchers are playing God," or suggested a general mistrust of science and scientists: "They just don't leave anything to chance, some things should be left alone." Respondents under 60 years old were over twice as likely to have a negative or mixed reaction as those 60 or over (odds ratio $=2.40 ; P<0.05$ ). Although significant in bivariate analysis, media source was not a significant predictor of initial reaction in the logistic regression, probably due to its strong association with age.

\section{Perceptions of media coverage}

When asked about the amount of media coverage surrounding the genome mapping announcement, half of all respondents (49.6\%) said that it was "just right," $27.4 \%$ thought there was too little coverage, and only $6.5 \%$ responded that there was too much coverage. When asked what they remembered about the content of media coverage, $51.7 \%$ of respondents recalled only positive messages and $7.4 \%$ of respondents thought the media message had to do with negative implications of the genome mapping. Several respondents $(n=15)$ commented on the motives of media or the scientists involved (e.g., "I think it was just PR"). A total of $11.7 \%$ of participants commented on both positive and negative aspects of the media coverage. The remaining $29.1 \%$ provided neither positive nor negative descriptions of media coverage. In addition to the particulars of what had been accomplished, a large proportion of these "neutral" responses had to do with the race between the government project and Celera Genomics. Perceptions of the media messages were not associated with respondent characteristics.

\section{Impact of the genome mapping}

When asked about the impact of mapping the human genome on people in general, the majority of respondents (52.2\%) mentioned positive as well as negative implications, $24.8 \%$ mentioned only positive implications, 9.1\% mentioned only negative implications, and the remaining $13.9 \%$ made comments that were neither positive nor negative. Responses to this question did not always correspond to initial reactions to the genome mapping announcement. The majority (64\%) of respondents whose initial reaction was entirely positive mentioned at least one negative consequence when asked about the impact of mapping the human genome. Conversely, $67 \%$ of respondents reporting a negative initial reaction mentioned one or more positive consequences that may result from the genome mapping.

Overall, $71 \%(n=163)$ of respondents said that the impact of the genome mapping on people will be the prevention and treatment of diseases. Of these 163 participants, 33\% believed such medical advances are already occurring or will occur within the next 5 years, $23 \%$ said advances will occur within 5 to 10 years, and $24 \%$ said it will be 10 or more years before such advances take place. Respondents who reported a positive ini- tial reaction to the genome mapping announcement were significantly more likely than those with at least a partially negative initial reaction to say that medical advances are already occurring or will occur within the next 5 years $(60.6 \%$ vs. $34.7 \%, P<0.05)$. In addition, women were more likely than men to believe that the benefits of mapping the genome are already being realized or will be realized within the next 5 years (50.7\% vs. $29.1 \%, P<0.05$ ).

A total of $61.3 \%$ of all consumers mentioned at least one possible negative outcome of mapping the human genome. The most frequently mentioned were privacy violations/discrimination (15.7\%) and cloning (13.5\%). Other concerns included an increase in abortions, patenting of genes, inequity in access to new technologies, and genetic enhancement. Some consumers expressed concern that sequencing and making use of the human genetic code is "playing God." Others were concerned about the possible actions of "unscrupulous scientists."

\section{Analysis of media reports}

Fifty-five media reports related to the genome mapping announcement that appeared between June 26 and July 3, 2000, were analyzed for general content. These reports included 18 newspaper articles, 3 magazine articles, 8 wire reports, 23 television broadcasts, and 3 radio broadcasts (see Table 3 for a list of media sources).

Table 4 presents the average proportion of paragraphs in newspaper/wire reports and television broadcasts devoted to each of the major content areas (because there were only three magazine and three radio reports in our sample and because

\section{Table 3}

Sources of media reports analyzed

\begin{tabular}{lc}
\hline & No. of reports \\
\hline United Press International & 2 \\
Associated Press & 6 \\
The New York Times & 1 \\
The Washington Post & 2 \\
The Baltimore Sun & 4 \\
USA Today & 2 \\
Time Magazine & 1 \\
Newsweek & 9 \\
CNN News & 5 \\
ABC News & 3 \\
CBS News & 3 \\
NBC News & 2 \\
CNBC News & 1 \\
The News Hour with Jim Lehrer & 3 \\
NPR & 55 \\
Total & \\
\hline
\end{tabular}


Table 4

Relative focus of media reports

\begin{tabular}{lcc}
\hline & $\begin{array}{c}\text { Newspaper/wire } \\
(N=26)\end{array}$ & $\begin{array}{c}\text { TV } \\
(N=23)\end{array}$ \\
\hline What was done & $21.7(26.0)$ & $11.1(8.2)$ \\
What remains to be done & $5.2(8.7)$ & $3.5(4.7)$ \\
Who was involved & $23.6(26.7)$ & $11.6(12.4)$ \\
Medical implications & $14.3(15.4)$ & $32.6(20.5)$ \\
Scientific implications & $2.7(7.5)$ & $2.6(6.2)$ \\
Ethical issues & $7.2(13.8)$ & $20.5(23.9)$ \\
Scientific limitations & $5.3(11.2)$ & $4.3(10.9)$ \\
Opinions of experts & $4.2(6.3)$ & $2.3(2.8)$ \\
Opinions of public leaders & $1.1(2.7)$ & $2.8(5.8)$ \\
Other & $14.9(19.9)$ & $10.7(11.9)$ \\
\hline
\end{tabular}

Data presented as mean $\% \pm \mathrm{SD}$.

these sources were less frequently cited by consumers, they were excluded from this analysis). Although there was wide variation in the content of media reports, newspaper/wire reports, on average, focused most heavily on "What was done" and "Who was involved." Substantial attention in the print media was given to describing the process that had taken place in mapping the human genome and the competition and ultimate collaboration between the government project and Celera.

In contrast, television news reports focused more on "Medical implications" and "Ethical issues" related to the genome mapping. In the discussions of medical implications, $82 \%$ of television and newspaper/wire reports referred to the ability to predict disease, $74 \%$ talked about disease prevention, and $78 \%$ discussed the potential for developing new treatments for disease as a result of mapping the human genome.

With regard to possible ethical issues resulting from the mapping of the human genome, privacy concerns ( $43 \%$ of newspaper/wire and television reports) and genetic discrimination (49\%) were the most frequently cited. Thirtythree percent of the reports specifically mentioned the potential for insurance discrimination, and 25\% talked about job discrimination. Other ethical concerns addressed by the media reports included patenting of genes (25\%) and "designer babies" $(20 \%)$.

\section{DISCUSSION}

As anticipated, news of the nearly complete map of the human genome reached a large audience. Over half of the individuals we surveyed reported some exposure to media coverage of the event. Reactions to the announcement were mixed, with optimism about the future medical benefits resulting from the Human Genome Project tempered by concern about possible risks and abuses. A 1992 study in England yielded very similar results. ${ }^{15}$ The authors described a "Discourse of Great
Promise" and a "Discourse of Concern" in focus group discussions about new genetic technologies. Durant et al. also found that discussions about the "new human genetics" that took place early in focus groups tended to be more positive than negative, but toward the end, the balance of discussion shifted toward more negative reactions. Similarly, we found that although a majority of respondents had a positive first reaction to the announcement that the human genome had been mapped, most were able to cite at least one negative consequence when asked later in the interview about the impact of mapping the human genome on people in general.

We found that African Americans were much more likely to voice an initially negative reaction to the genome mapping than Caucasians. This finding was true regardless of educational level. Although they were no more likely to cite concerns about privacy or other ethical issues, African Americans were significantly more likely than Caucasians to voice religious concerns or to express mistrust of science and scientists. Others have emphasized the lack of trust many African Americans feel toward the medical profession and biomedical research, ${ }^{17-19}$ as well as possible gaps between the concerns of policy makers and African Americans with regard to genetic services..$^{20}$ Our data further highlight the importance of including minority views in future research and discussions about ethical and policy issues related to mapping the human genome.

We also found a difference in initial reactions to the genome mapping by age, with those age 60 or over significantly less likely than those under age 60 to mention negative consequences in describing their initial reactions to the genome mapping. This difference may reflect a tendency for older Americans to have more trust in the medical-scientific community. Alternatively, older individuals may have a greater personal concern about the diseases the Human Genome Project promises to address (e.g., cancer, Alzheimer's disease) and therefore, are more hopeful about the prospects for improved treatment than younger individuals.

When asked about the significance of the human genome mapping for people, the vast majority of respondents referred to the potential to prevent and cure disease. This finding is consistent with media coverage of the event, and television coverage in particular. However, there was substantial variability in respondents' beliefs about when such benefits would be realized. Although a third of respondents thought benefits were already being realized or would be within the next 5 years, a sizable proportion thought it would be 10 years or more before such medical advances take place. This difference reflects variation in media reports concerning the timing of medical advances. Views regarding the timing of medical advances resulting from the Human Genome Project were associated with initial reactions to the genome mapping such that those who believed new interventions were already or would soon become available were more likely to have a positive reaction.

The potential for privacy violations and discrimination were the ethical concerns most frequently mentioned by consumers when discussing the impact of the genome mapping. This con- 
cern is not surprising given that these issues were by far the most frequently cited by the media. The patenting of genes was also frequently included in media coverage but rarely mentioned by consumers. It is not clear whether this finding is because people are not concerned about gene patenting or because they do not understand it or its implications.

Human cloning was another ethical concern mentioned by a substantial number of respondents. This finding is interesting given that, in all of the media reports we analyzed, cloning was never mentioned as a possible outcome of the Human Genome Project. This finding lends support to a comment by the head of the Human Genome Project, Francis Collins, that people tend to “. . lump anything with 'gen' as the human genome project-gene therapy, GM foods, cloning - it's all the same thing." ${ }^{21}$ Although the media may not directly associate cloning with the Human Genome Project, it is a genetics-related topic that is frequently reported in the popular press. ${ }^{22}$ Recent reports of plans to attempt human cloning have brought the issue again into the public eye. Dramatic magazine covers are likely to influence public reactions to the prospect of human cloning ${ }^{23,24}$ and may, perhaps, lead to an overgeneralization to other areas of human genetic research.

We found, as described by Durant et al., ${ }^{15}$ that ethical issues were commonly mentioned in media reports about new genetic technologies, but media reporting of these issues tended to be brief and "formulaic." In our study, discussion of ethical issues related to the human genome mapping accounted for $5 \%$ or less of the overall article content in $75 \%$ of the newspaper/wire reports we analyzed. Ethical issues accounted for a somewhat larger proportion of television broadcasts. Discussion of issues such as privacy, discrimination, and "genetic enhancement" were generally limited in scope and depth.

The present study has several limitations. First, there was a fairly high rate of refusal to the telephone survey. Many individuals refused to speak with the interviewers before even learning what the survey was about, and we have no information about refusers. Therefore, it is not clear to what extent those who agreed to participate in our survey are different from those who refused. Second, our survey was limited to Maryland residents; therefore, we do not know how our results would compare with surveys in other geographic regions. We also were only able to analyze the subset of media coverage most relevant to our survey respondents. An exhaustive review of the media coverage related to the June 2000 human genome announcement was beyond the scope of this study. Finally, although we found significant differences in the reactions of African Americans in our survey, our ability to generalize this finding is limited by the small number of African Americans in our sample.

\section{CONCLUSIONS}

Although it cannot be the sole responsibility of the media to inform people about human genetic research, the mass media are a major forum for discussion in our society and the most expedient method of disseminating information to a broad audience. Efforts should be made by both the scientific community and the media to identify and address the informational needs of people from diverse cultural and socioeconomic backgrounds. If, as has been previously asserted, ${ }^{14}$ the public has a right to play a role in determining the future direction of genetic research, the public must be better informed about the issues at stake.

Members of the mass media might facilitate this important public debate by raising issues for discussion beyond the sporadic reporting of major genetic breakthroughs and milestones, and by attempting a more nuanced presentation of the important ethical and societal issues. Reporting of the more extraordinary aspects of human genetics such as cloning should not overshadow the reporting of issues with more immediate relevance to the public, such as genetic susceptibility testing. Finally, in addition to explaining to the public what the Human Genome Project is, scientists and journalists should make a concerted effort to explain what it is not.

\section{Acknowledgments}

This work was supported by a grant (R01 HGO1871-03) from the National Human Genome Research Institute. We thank Veronica Clay for her endless hours of coding and data processing and Pat Linzey and Scott McBride for their help in carrying out the telephone survey.

\section{References}

1. Federal News Service. Special White House Briefing. June 26, 2000.

2. Larkin M. Making sense of genome mania. Lancet 2000;356:263.

3. Editorial. The end of the beginning. Nat Genet 2000;25:363-364.

4. Wildner M. Aristotle and the human genome project. Lancet 2000;356:1360.

5. Friedrich MJ. Relating genomic research to patient care. JAMA 2000;284:2581-2582.

6. US General Social Survey. Chicago: National Opinion Research Center, 1990;

7. March of Dimes Birth Defects Foundation. Genetic testing and gene therapy: National survey findings, 1992.

8. Jallinoja P, Hakonen A, Aro AR, Niemela P, Hietala M, Lonnqvist J, Peltonen L, Aula P. Attitudes towards genetic testing: Analysis of contradictions. Soc Sci Med 1998; 46:1367-1374.

9. National Science Foundation. Survey of public understanding of science and technology, 1990.

10. Golden F, Lemonick MD. The race is over. Time July 3, 2000:19.

11. Conrad P, Gabe J. Introduction. Sociological perspectives on the new genetics: an overview. Soc Health Illness 1999;21:505-516.

12. Stockdale A. Public understanding of genetics and Alzheimer disease. Genet Test 1999;3:139-145.

13. Petersen A. Biofantasies: genetics and medicine in the print news media. Soc Sci Med 2001;52:1255-1268.

14. Priest SH. Popular beliefs, media, and biotechnology. In: Friedman SM, Dunwoody S, Rogers CL, editors. Communicating uncertainty: Media coverage of new and controversial science. New Jersey: Lawrence Erlbaum Associates, 1999:95-112.

15. Durant J, Hansen A, Bauer M. Public understanding of the new genetics. In: Marteau T, Richards M, editors. The troubled helix: social and psychological implications of the new human genetics. Cambridge: Cambridge University Press, 1996.

16. Furr LA, Kelly SE. The genetic knowledge index: developing a standard measure of genetic knowledge. Genetic Test 1999;3:193-199.

17. Mittman IS, Secundy MG. A national dialogue on genetics and minority issues. Community Genet 1998;1:190-200.

18. Roberts DE. The nature of Blacks' skepticism about genetic testing. Seton Hall Law Rev 1997;27:971-979.

19. Freimuth VS, Crouse Quinn S, Thomas SB, Cole G, Zook E, Duncan T. African Americans' views on research and the Tuskegee Syphilis Study. Soc Sci Med 2001;52:797-808.

20. Wertz DC. The difficulties of recruiting minorities to studies of ethics and values in genetics. Community Genet 1998;1:175-179.

21. Lewis R. Francis Collins preaches to the choir. The Scientist November 13, 2000.

22. Hopkins PD. Bad copies. How popular media represent cloning as an ethical problem. Hastings Cent Rep 1998;28:6-13.

23. Gibbs N. Baby it's you! and you and you... . Time February 19, 2001.

24. Talbot M. Lab of the human clones. New York Times February 4, 2001;6:1. 